https://helda.helsinki.fi

Intraoperative colonic pulse oximetry in left-sided colorectal surgery : can it predict anastomotic leak?

Salusjärvi, Johannes M.

2018-03

Salusjärvi , J M , Carpelan-Holmström , M A , Louhimo , J M , Kruuna , O \& Scheinin , T M 2018 , ' Intraoperative colonic pulse oximetry in left-sided colorectal surgery : can it predict anastomotic leak? ' , International Journal of Colorectal Disease, vol. 33 , no. 3 , pp.

333-336 . https://doi.org/10.1007/s00384-018-2963-4

http://hdl.handle.net/10138/300769

https://doi.org/10.1007/s00384-018-2963-4

publishedVersion

Downloaded from Helda, University of Helsinki institutional repository.

This is an electronic reprint of the original article.

This reprint may differ from the original in pagination and typographic detail.

Please cite the original version. 


\title{
Intraoperative colonic pulse oximetry in left-sided colorectal surgery: can it predict anastomotic leak?
}

\author{
Johannes M. Salusjärvi ${ }^{1,2}$ • Monika A. Carpelan-Holmström ${ }^{3}$ • Johanna M. Louhimo ${ }^{2,3}$ - Olli Kruuna ${ }^{3}$ • \\ Tom M. Scheinin ${ }^{3}$
}

Accepted: 11 January 2018 / Published online: 26 January 2018

(C) Springer-Verlag GmbH Germany, part of Springer Nature 2018

\begin{abstract}
Background An anastomotic leak is a fairly common and a potentially lethal complication in colorectal surgery. Objective methods to assess the viability and blood circulation of the anastomosis could help in preventing leaks. Intraoperative pulse oximetry is a cheap, easy to use, fast, and readily available method to assess tissue viability. Our aim was to study whether intraoperative pulse oximetry can predict the development of an anastomotic leak.

Methods The study was a prospective single-arm study conducted between the years 2005 and 2011 in Helsinki University Hospital. Patient material consisted of 422 patients undergoing elective left-sided colorectal surgery. The patients were operated by one of the three surgeons. All of the operations were partial or total resections of the left side of the colon with a colorectal anastomosis. The intraoperative colonic oxygen saturation was measured with pulse oximetry from the colonic wall, and the values were analyzed with respect to post-operative complications.

Results 2.3 times more operated anastomotic leaks occurred when the colonic $\mathrm{StO}_{2}$ was $\leq 90 \%(11 / 129 \mathrm{vs} 11 / 293)$. The mean colonic $\mathrm{StO}_{2}$ was 91.1 in patients who developed an operated anastomotic leak and 93.0 in patients who did not. With logistic regression analysis, the risk of operated anastomotic leak was 4.2 times higher with $\mathrm{StO}_{2}$ values $\leq 90 \%$.

Conclusions Low intraoperative colonic $\mathrm{StO}_{2}$ values are associated with the occurrence of anastomotic leak. Despite its handicaps, the method seems to be useful in assessing anastomotic viability.
\end{abstract}

Keywords Anastomotic leak · Colorectal surgery · Oximetry

\section{Introduction}

A leak in a colorectal anastomosis increases morbidity, mortality, risk of a poor oncological outcome, and length of hospital stay [1-3]. Despite its pivotal role as a complication, the definitive consensus of the definition of anastomotic leak (AL) is still lacking [4]. Depending on the patient material,

Johannes M. Salusjärvi

johannes.salusjarvi@helsinki.fi

1 Department of Surgery, Päijät-Häme Central Hospital and University of Helsinki, Keskussairaalankatu 7, Lahti 15850, Finland

2 University of Helsinki, Helsinki, Finland

3 Department of Surgery, Abdominal Center, Helsinki University Hospital, Haartmaninkatu 4, PL 340, 00029 Helsinki, HUS, Finland hospital, site of anastomosis, and definition, the rate of $\mathrm{AL}$ varies between 1 and 30\% although 3-6\% is often quoted as an acceptable overall leak rate [5].

Many studies can be found about the risk factors for AL. The results are inconclusive, but some risk factors come up in most of the studies: male gender, chronic steroid use, ASA (American Society of Anesthesiologists) classification, intraoperative blood loss, obesity, smoking, alcohol abuse, long operation time, low anastomose, and neoadjuvant radiation therapy $[2,5-7]$.

Assessment of the tissue viability is made by the operating surgeon, mostly based on tissue color and the amount of bleeding. Measuring tissue blood flow/oxygenation by means of laser Doppler flowmetry, hemoglobin oxygenation spectroscopy, etc. [8-10] has shown promising results in detecting anastomoses susceptible to leak. These methods, however, require special equipment and have not been adequately studied within larger patient series. Perioperative supplemental 
oxygen administration has also been speculated to decrease the risk of AL [11]. The main goal of our study was to determine whether anastomotic tissue oxygenation measured by a cheap and commonly available pulse oximetry probe correlates with anastomotic leak.

\section{Materials and methods}

The patient material of the study was identified from all of the patients who underwent elective left-sided colorectal surgery with colorectal anastomosis (sigmoid colectomy, left hemicolectomy, or anterior resection) by one of the three surgeons (M.C-H, O.K, T.S). $92.4 \%$ of the operations were laparoscopic. The operations were done in Helsinki University Hospital between the years 2005 and 2011.

Clinical data was collected from preoperative anesthesia questionnaires, perioperative anesthesia forms, and patients' medical records. The acquisition of this data was approved by our institutional review board. All of the patients were treated by the local standard of care.

The colonic hemoglobin oxygen saturation levels $\left(\mathrm{StO}_{2}\right)$ were measured after the division of the mesentery at the place where the bowel was planned to be divided. Equipment used for measuring consisted of a Datex Ohmeda S/5 (GE Healthcare Finland, Helsinki) monitor and a connected pulse oximetry probe. The probe has a light source that emits red and infrared light (660 and $910 \mathrm{~nm}$ ) and a light sensor. The arterial hemoglobin oxygen saturation level is calculated from the pulsative part of the light signal by analyzing the amount of light absorbed by hemoglobin.

Sixty-eight patients did not have a recorded colonic $\mathrm{StO}_{2}$ value; a total of 422 patients with a recorded pulse oximetry value were included in the statistical analyses.

The anastomotic leaks were categorized in two groups: major leaks requiring re-operation (Clavien-Dindo classification grade IIIb and up) and confined, smaller leaks treated conservatively (grade I-IIIa) [12].

Re-operated major ALs were chosen as the main end point. Differences between patients with operated AL and other patients were analyzed using chi-square test for independence for categorical variables and Mann-Whitney $U$ test for continuous variables. A logistic regression analysis was performed to assess the variables that had a significant association with operated AL.

Associations between measured $\mathrm{StO}_{2}$ values and other variables were examined using Mann-Whitney $U$ test for variables with two categories and Kruskal-Wallis test for variables with three or more categories. Continuous variables were first analyzed using Spearman's rho and correlating $(p<0.1)$ variables were then binned and analyzed.

The data was analyzed using IBM SPSS statistics software version 22 (IBM Corp. Armonk, NY, USA).

\section{Results}

The amount of AL complications was 31/422 (7\%). Nine of these were small leaks that were treated with antibiotics and/or drainage, whereas 22/422 (5\%) had an AL that required reoperation.

AL had significant association with eight variables. Males were at a higher risk ( 7.8 vs $3.3 \%), p=0.041$. The risk of developing an AL depended on the type of primary operation done; the risk was small with sigmoid colectomies $(2.3 \%)$ compared to left hemicolectomies $(11.9 \%)$ and anterior resections $(15.2 \%), p=0.000$. Converting the operation (14.8 vs $4.4 \%), p=0.020$, long operation time (159.5 vs $134.1 \mathrm{~min})$, $p=0.016$, and heavy bleeding (325.7 vs $162.9 \mathrm{ml}), p=0.010$, was also an independent risk factor. Patients with no longterm illnesses had a smaller AL rate (1.7 vs 6.5\%), $p=0.049$.

The main variable of interest, colonic $\mathrm{StO}_{2}$, was lower in patients who developed an AL (91.1 vs 93.0) like the study hypothesis suggests; however, this difference was not significant, $p=0.292$. The rest of the variables (age, BMI, ASA class, indication of operation, TN class, oxygen concentration of inhalation gas, previous operations, smoking status) did not have a significant association with AL.

When the patients were divided into groups according to the $\mathrm{StO}_{2}$ value, AL occurred at a higher rate among the groups with lower $\mathrm{StO}_{2}$ value. With $\mathrm{StO}_{2} 90 \%$ defined as the cut-off point, the risk of AL was significantly higher in patients who had $\mathrm{StO}_{2} \leq 90, p=0.042$. The results are presented in Fig. 1 .

The association of the $\mathrm{StO}_{2}$ values and other variables was also examined and significant association with $\mathrm{StO}_{2}$ was found with five variables:

Patients operated due to a tumor had lower $\mathrm{StO}_{2}$ (cancer 91.8, benign tumor 91.8) than other patient groups (diverticulosis 93.4, volvulus 96.2, other 95.3), $p=0.047$. Older patients had lower $\mathrm{StO}_{2}$, when patients were grouped in five groups with 15 year intervals, $p=0.04$. The mean $\mathrm{StO}_{2}$ was

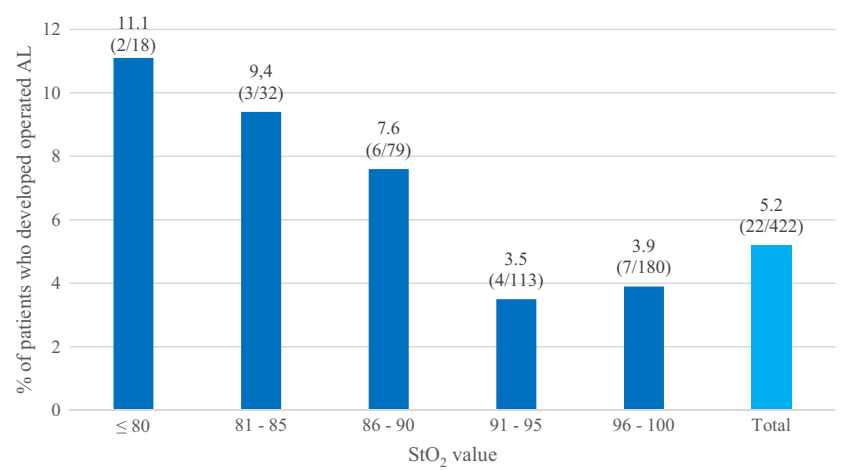

Fig. 1 The patients are divided into groups according to the $\mathrm{StO}_{2}$ value. The bars represent the percentage of patients within the $\mathrm{StO}_{2}$ range who developed an operated AL. Chi-square test for independence gives a $p$ value of 0.334 for the $\mathrm{StO}_{2}$ groups above. If the groups are narrowed to two, $\mathrm{StO}_{2} \leq 90$ and $\mathrm{StO}_{2}>90$, we get a $p$ value of 0.042 and a risk ratio of 2.3 for developing an operated $\mathrm{AL}$ if $\mathrm{StO}_{2}$ is $\leq 90 \%$ 
94.6 with patients under 35 years and 87.8 with patients over 80. Lower $\mathrm{StO}_{2}$ levels were found in patients with diabetes (91.1 vs 93.0), $p=0.03$, hypertension (92.2 vs 93.3$), p=$ 0.046 , and dyslipidemia (91.5 vs 93.2), $p=0.01$.

The variables with a significant association with $\mathrm{AL}$ in the logistic regression analysis were the type of operation, smoking, conversion, and colonic $\mathrm{StO}_{2}$. The odds ratio (OR) for developing an $\mathrm{AL}$ requiring re-operation was 0.24 when colonic $\mathrm{StO}_{2}$ was $>90 \%$, and the risk for a leak was 4.2 times higher when $\mathrm{StO}_{2}$ was $\leq 90 \%, p=0.008$. The $\mathrm{OR}$ for $\mathrm{AL}$ was 3.432 for smoking, $p=0.025,10.538$ for left hemicolectomy, $p=0.000,10.561$ for anterior resection, $p=0.004$ (vs sigmoid colectomy), 2.995 for conversion, $p=0.147$, and 14.422 if open from beginning, $p=0.031$ (vs not converted). The same logistic regression model was also run with all AL complications as the end point. In this analysis, conversion was not significant; otherwise, the results were similar.

Sixty-eight (13.9\%) patients had to be omitted because $\mathrm{StO}_{2}$ value was not available. Because of this, $29 \%$ (9/31) of the operated ALs were not included in the analyses. Differences between the excluded and the included patient groups were analyzed using chi-square test for independence for categorical variables and Mann-Whitney $U$ test for continuous variables. Significant differences were found in ten variables. Excluded patients were older (63.6 vs 59.9 years) and had a higher ASA class, the ratio of operations due to tumor was higher, the ratio of anterior resections was higher, operations lasted longer (152.4 vs $135.4 \mathrm{~min}$ ), intraoperative blood loss was higher (395.6 vs $172.4 \mathrm{ml}$ ), the length of hospital stay was longer (8.1 vs 4.8 days), the rate of anastomotic leak as well as other complications was higher, and the rate of operations converted was higher.

\section{Discussion}

Colonic oxygen saturation is significantly associated with the occurrence of AL. Re-operated ALs occurred 2.3 times more often when the colonic $\mathrm{StO}_{2}$ was $\leq 90 \%$. Other significant risk factors for $\mathrm{AL}$ were the type of operation performed, operation length and blood loss, conversion, male sex, and having longterm illnesses. In the logistic regression, the type of operation, smoking, conversion, and colonic $\mathrm{StO}_{2}$ were significant risk factors for AL. Low anastomosis (type of operation performed), operation length, intraoperative blood loss, male sex, and smoking have been found as risk factors for $\mathrm{AL}$ in previous studies as well [2, 5-7].

AL occurred more often in patients operated due to a tumor (AL rate $8.5 \%$ with cancer, $7.7 \%$ with benign tumor, and $3.3 \%$ with diverticulosis) although this difference was not significant, $p=0.116$. The difference could be explained by the more radical transection of arteries when operating tumors. This is also likely to be the reason for lower $\mathrm{StO}_{2}$ values in this group.
Patients of whom the $\mathrm{StO}_{2}$ was not recorded were older, and the operations were more challenging (longer operation time, higher blood loss, cancer vs diverticulosis, anterior resection vs sigmoid colectomy, more conversions). This explains in part why the $\mathrm{StO}_{2}$ was not measured (the surgeon was too busy with the operation).

The disadvantage of pulse oximetry is that it measures the oxygenated hemoglobin rate that travels in the tissue during a pulse and therefore measures the hemoglobin oxygenation rate of arterial blood. It does not fully reflect the local tissue oxygenation. Even with well-oxygenated arterial blood, the blood flow to the tissue might be insufficient.

In conclusion, measuring colonic $\mathrm{StO}_{2}$ does seem to give information on the viability of the anastomosis. This method is cheap and easy to use and despite its disadvantages, low $\mathrm{StO}_{2}$ levels do indicate a higher risk for $\mathrm{AL}$.

Compliance with ethical standards The acquisition of this data was approved by our institutional review board. All of the patients were treated by the local standard of care.

Conflict of interest The authors declare that they have no conflict of interest.

\section{References}

1. Kube R, Mroczkowski P, Granowski D, Benedix F, Sahm M, Schmidt U, Gastinger I, Lippert H (2010) Anastomotic leakage after colon cancer surgery: a predictor of significant morbidity and hospital mortality, and diminished tumour-free survival. Eur J Surg Oncol 36(2):120-124. https://doi.org/10.1016/j.ejso.2009.08. 011

2. Boccola MA, Buettner PG, Rozen WM, Siu SK, Stevenson AR, Stitz R, Ho YH (2011) Risk factors and outcomes for anastomotic leakage in colorectal surgery: a single-institution analysis of 1576 patients. World J Surg 35(1):186-195. https://doi.org/10.1007/ s00268-010-0831-7

3. Mirnezami A, Mirnezami R, Chandrakumaran K, Sasapu K, Sagar P, Finan P (2011) Increased local recurrence and reduced survival from colorectal cancer following anastomotic leak: systematic review and meta-analysis. Ann Surg 253(5):890-899. https://doi.org/ 10.1097/SLA.0b013e3182128929

4. Adams K, Papagrigoriadis S (2013) Little consensus in either definition or diagnosis of a lower gastro-intestinal anastomotic leak amongst colorectal surgeons. Int J Color Dis 28(7):967-971. https://doi.org/10.1007/s00384-013-1640-x

5. Kingham TP, Pachter HL (2009) Colonic anastomotic leak: risk factors, diagnosis, and treatment. J Am Coll Surg 208(2):269278. https://doi.org/10.1016/j.jamcollsurg.2008.10.015

6. Park JS, Choi GS, Kim SH, Kim HR, Kim NK, Lee KY, Kang SB, Kim JY, Lee KY, Kim BC, Bae BN, Son GM, Lee SI, Kang H (2013) Multicenter analysis of risk factors for anastomotic leakage after laparoscopic rectal cancer excision: the Korean laparoscopic colorectal surgery study group. Ann Surg 257(4):665-671. https:// doi.org/10.1097/SLA.0b013e31827b8ed9

7. Trencheva K, Morrissey KP, Wells M, Mancuso CA, Lee SW, Sonoda T, Michelassi F, Charlson ME, Milsom JW (2013) Identifying important predictors for anastomotic leak after colon 
and rectal resection: prospective study on 616 patients. Ann Surg 257(1):108-113. https://doi.org/10.1097/SLA.0b013e318262a6cd

8. Karliczek A, Benaron DA, Baas PC, Zeebregts CJ, Wiggers T, van Dam GM (2010) Intraoperative assessment of microperfusion with visible light spectroscopy for prediction of anastomotic leakage in colorectal anastomoses. Color Dis 12(10):1018-1025. https://doi.org/10.1111/j.1463-1318.2009. 01944.X

9. Hirano Y, Omura K, Tatsuzawa Y, Shimizu J, Kawaura Y, Watanabe $\mathrm{G}$ (2006) Tissue oxygen saturation during colorectal surgery measured by near-infrared spectroscopy: pilot study to predict anastomotic complications. World J Surg 30(3):457-461. https:// doi.org/10.1007/s00268-005-0271-y
10. Vignali A, Gianotti L, Braga M, Radaelli G, Malvezzi L, Di Carlo V (2000) Altered microperfusion at the rectal stump is predictive for rectal anastomotic leak. Dis Colon Rectum 43(1):76-82. https://doi. org/10.1007/BF02237248

11. Garcia-Botello SA, Garcia-Granero E, Lillo R, Lopez-Mozos F, Millan M, Lledo S (2006) Randomized clinical trial to evaluate the effects of perioperative supplemental oxygen administration on the colorectal anastomosis. Br J Surg 93(6):698-706. https:// doi.org/10.1002/bjs.5370

12. Dindo D, Demartines N, Clavien PA (2004) Classification of surgical complications: a new proposal with evaluation in a cohort of 6336 patients and results of a survey. Ann Surg 240(2):205-213. https://doi.org/10.1097/01.sla.0000133083.54934.ae 